\title{
Coactivator-mediated estrogen response in human squamous cell carcinoma lines
}

\author{
Tony K S Ku and David L Crowe \\ University of Illinois Cancer Center, Center for Molecular Biology of Oral Diseases, University of Illinois at Chicago, 801 South Paulina Street, Chicago, Illinois \\ 60612, USA \\ (Requests for offprints should be addressed to D L Crowe; Email: dlcrowe@uic.edu)
}

\begin{abstract}
Steroid hormones such as $17 \beta$-estradiol (E2) are critical to diverse cellular processes including tumorigenesis. A number of cofactors such as nuclear receptor corepressor (NCoR), CREB-binding protein (CBP), and steroid receptor coactivator 1 (SRC-1) interact with estrogen receptors (ERs) to regulate transcriptional repression or activation of target genes. Estrogen signaling in non-reproductive tract tissues such as skin is less well characterized and the effectiveness of anti-estrogen therapy for cancer arising from these tissues is unknown. We show that tamoxifen (TAM) treatment inhibited cell cycle progression and proliferation of human cancer lines derived from stratified squamous epithelium squamous cell carcinoma (SCC). E2 had no effect on proliferation of these lines despite low levels of ER $\alpha$ expression. The E2 treatment promoted displacement of the $\mathrm{NCoR}$ from $\mathrm{ER} \alpha$ and recruitment of $\mathrm{CBP}$ to the receptor.
\end{abstract}

SRC-1 expression was not detected in these SCC lines; however, transient transfection of SRC-1, CBP, or both coactivators enhanced transactivation of an estrogen responsive promoter in cancer cells treated with E2 or TAM. In stable clones expressing SRC-1, the coactivator was recruited to $\mathrm{ER} \alpha$ along with CBP in E2 but not in TAM-treated cells. SRC-1 expression restored the E2-mediated proliferative response to human SCC lines. This increased proliferation correlated with increased extracellular signal regulated kinase 1 (ERK1) expression. SRC-1 and CBP were recruited to the proximal ERK1 promoter region in E2 but not in TAMtreated cells. We concluded that SRC-1 was a key molecular determinant of estrogen-mediated proliferation in human SCC lines.

Journal of Endocrinology (2007) 193, 147-155

\section{Introduction}

Steroid hormones such as $17 \beta$-estradiol (E2) are critical to diverse cellular processes including development, reproduction, and tumorigenesis (Kim et al. 2001). The E2 functions through its receptors ER $\alpha$ and ER $\beta$ (Couse \& Korach 1999). ERs belong to the superfamily of nuclear hormone receptors that are ligand-dependent transcription factors (Mangelsdorf et al. 1995). The ER $\alpha$ binds to estrogen response elements in the promoters of responsive genes. A number of cofactors interact with $\mathrm{ER} \alpha$ to regulate transcriptional repression or activation. Among the repressive cofactors is nuclear receptor corepressor (NCoR), which interacts with $\mathrm{ER} \alpha$ in the presence of the anti-estrogen 4-hydroxytamoxifen (TAM; Huang et al. 2002). Chimeric NCoR-ER $\alpha$ proteins have been shown to silence basal transcription of $\mathrm{ER} \alpha$ responsive genes (Chien et al. 1999). Dissociation of corepressors from $\mathrm{ER} \alpha$ correlates with estrogen-dependent responses (Carroll et al. 2003). Loss of corepressor interaction with ER $\alpha$ leads to recruitment of coactivators, which serve to recruit other cofactors, acetylate nucleosomal histones, and bind basal transcriptional machinery (Ratajczak 2001). Histone acetylation results in more open chromatin structure and increased transcriptional activity (Kornberg \& Lorch 1999). Interactions between activated ER $\alpha$ bound to DNA and coactivators such as steroid receptor coactivator 1 (SRC-1) and CREB-binding protein (CBP) regulate the transcription of estrogen target genes (Robyr et al. 2000).

SRC-1 functions primarily as coactivator for nuclear receptors and binds directly to liganded ER $\alpha$ through helical LXXLL motifs (Needham et al. 2000). The SRC-1 contributes to transcriptional activation by interacting with other coactivators such as CBP (Smith et al. 1996, Sheppard et al. 2001). Coactivators such as SRC-1 and CBP possess histone acetyltransferase activity, which can disrupt nucleosomal structure leading to transcriptional activation (Spencer et al. 1997). Disruption of the $S R C-1$ gene in mice leads to partial hormone resistance in target organs such as uterus, prostate, testis, and mammary gland (Xu et al. 1998).

The estrogen response in non-reproductive tract tissues such as skin and other stratified squamous epithelia is less well characterized. Estrogen has clinically important functions in epidermis, hair follicles, and secretory glands (for review see Thornton 2002). The E2 treatment increased proliferation and 
thickness of epidermis in wild-type but not ER $\alpha$ in null mutant mice (Moverare et al. 2002); E2 enhanced proliferation of human keratinocytes in vitro by inducing cyclin D2 expression (Kanda \& Watanabe 2004). In human clinical trials, E2 treatment increased epidermal thickness and reduced the prevalence of histologic features associated with aging (Fuchs et al. 2003). E2 increased expression of type I collagen, tropoelastin, fibrillin-1, and elastic fibers in aged skin in vivo (Son et al. 2005). These studies indicate that ER $\alpha$ signaling can increase keratinocyte proliferation and extracellular matrix production in human skin cells in vivo and in vitro.

Conversely, treatment with antiestrogens, such as TAM, inhibits proliferation of estrogen-responsive cancer cells. Proliferation of breast and ovarian cancer cell lines was inhibited by TAM (Lindner \& Borden 1997, Cariou et al. 2000). High doses of antiestrogens have also been shown to inhibit proliferation and induce apoptosis in an ER $\alpha$ negative ovarian carcinoma cell line (Ercoli et al. 1998). However, the mechanism by which TAM inhibits proliferation of cancer cells from non-reproductive tissues such as stratified squamous epithelium is not well characterized. Furthermore, ER $\alpha$ expression is reportedly low in stratified squamous epithelia from different anatomic sites (Ojanotko-Harri et al. 1992). Coactivator expression and interaction with $\mathrm{ER} \alpha$ in regulating cancer cell proliferation from this tissue are largely unknown. We demonstrate that TAM but not E2 regulates cell cycle progression and proliferation of human squamous cell carcinoma (SCC) lines. We show that the SRC-1 coactivator protein is a key molecular determinant of this differential response to ER $\alpha$ signaling.

\section{Materials and Methods}

\section{Cell culture and stable transfection}

The human SCC lines used in this study were purchased from the American Type Culture Collection. Cells were cultured in Dulbecco's modified Eagle medium without phenol red, $10 \%$ charcoal-stripped fetal bovine serum, $40 \mu \mathrm{g} / \mathrm{ml}$ gentamicin at $37^{\circ} \mathrm{C}$ in a humidified atmosphere of $5 \% \mathrm{CO}_{2}$. SCC4, SCC9, or SCC25 cells were transfected with $5 \mu \mathrm{g}$ human SRC-1 expression vector (kindly provided by $\mathrm{Dr}$ Ronald Evans) or neomycin-resistance plasmid alone using Lipofectamine reagent according to the manufacturer's recommendations (Invitrogen). Cells were selected in $400 \mu \mathrm{g} / \mathrm{ml} \mathrm{G} 418$ for 14 days. Resistant clones were picked for expansion and characterization. The human breast cancer cell lines MCF7 (ER $\alpha$ positive) and MDA-MB-231 (ER $\alpha$ negative) were used as well characterized controls for ER $\alpha$ expression.

\section{Cell proliferation and BrdU incorporation analysis}

Triplicate cultures of $5 \times 10^{4}$ parental SCC lines, SRC-1, or vector control clones were plated into six-well plates and treated with 10-1000 nM E2 or 4-hydroxytamoxifen for up to 6 days. The control cultures were treated with $0 \cdot 1 \%$ ethanol vehicle for the same time period and they were trypsinized and counted at 2-day intervals using a hemacytometer. For bromodeoxyuridine (BrdU) incorporation analysis, cells were treated with ligands or vehicle for 1 day followed by $1-\mathrm{h}$ incubation in $10 \mu \mathrm{M}$ BrdU. After washing in PBS, cells were fixed in 70\% ethanol, $50 \mathrm{mM}$ glycine ( $\mathrm{pH} 2$ ) for $30 \mathrm{~min}$ at $-20^{\circ} \mathrm{C}$. After extensive washing in PBS, cells were incubated with mouse anti-BrdU primary antibody at $37^{\circ} \mathrm{C}$ for $30 \mathrm{~min}$ (Roche Molecular Biochemicals). After washing in PBS, cells were incubated with anti-mouse IgG secondary antibody conjugated to fluorescein at $37^{\circ} \mathrm{C}$ for $30 \mathrm{~min}$. Following extensive washing in PBS, BrdU-positive cells were visualized by fluorescence microscopy. The number of positive cells was expressed as a percentage of total cells counted in ten randomly selected high power fields.

\section{Reverse transcription-PCR}

RNA was extracted from SCC and breast cancer cell lines using a commercially available kit (Qiagen) and reverse transcribed using SuperScript II reverse transcriptase according to the manufacturer's instructions (Invitrogen). cDNA was amplified using ER $\alpha$ specific primers $\left(5^{\prime}-\right.$ CCACCAACCAGTGCACCATT- $3^{\prime}$ and $5^{\prime}$-GGTCTT TTCGTATCCCACCTTTC-3 $\left.{ }^{\prime}\right)$ in $20 \mathrm{mM}$ Tris- $\mathrm{HCl}(\mathrm{pH}$ 8.3), $1.5 \mathrm{mM} \mathrm{MgCl}_{2}, 63 \mathrm{mM} \mathrm{KCl,} \mathrm{0.05 \%} \mathrm{Tween} \mathrm{20,} 1 \mathrm{mM}$ EGTA, $50 \mu \mathrm{M}$ of each dNTP, and $2.5 \mathrm{U}$ Taq DNA polymerase (Roche Molecular Biochemicals). Amplification with $\beta$-actin cDNA using primers $5^{\prime}$-ACAGGAAGT CCCTTGCCATC-3' and 5'-ACTGGTCTCAAGTCAG TGTACAGG-3' as the internal control was carried out by real-time PCR (iCycler, BioR ad) using cycle parameters $94{ }^{\circ} \mathrm{C}$ for $25 \mathrm{~s}, 55^{\circ} \mathrm{C}$ for $1 \mathrm{~min}$, and $72{ }^{\circ} \mathrm{C}$ for $1 \mathrm{~min}$.

\section{Immunoprecipitation and western blot}

Cultures of ligand or vehicle-treated SCC lines and clones were lysed in $50 \mathrm{mM}$ HEPES ( $\mathrm{pH} 7 \cdot 5$ ), $150 \mathrm{mM} \mathrm{NaCl}$, $1 \mathrm{mM}$ EDTA, 2.5 mM EGTA, $1 \mathrm{mM}$ dithiothreitol, 1\% Nonidet P-40, 10\% glycerol, and protease inhibitors for $30 \mathrm{~min}$ at $4{ }^{\circ} \mathrm{C}$. Lysates were centrifuged at $10000 \mathrm{~g}$ for $10 \mathrm{~min}$ and anti-human primary antibody to $\operatorname{ER} \alpha$ or preimmune IgG (Santa Cruz Biotechnology, Santa Cruz, CA, USA) was incubated with the supernatants for $1 \mathrm{~h}$ at $4{ }^{\circ} \mathrm{C}$. Antigen-antibody complexes were precipitated by incubation with protein $\mathrm{A} / \mathrm{G}$ agarose (Santa Cruz Biotechnology) for $1 \mathrm{~h}$ at $4{ }^{\circ} \mathrm{C}$. Immunoprecipitated protein complexes were washed thrice with $1 \mathrm{ml}$ lysis buffer and separated by SDS-PAGE as described below. The blots were incubated with anti-SRC-1, CBP, and NCoR antibodies to determine interaction with ER $\alpha$ in cellular lysates and also stripped and incubated with anti-ER $\alpha$ antibody to determine the amount of immunoprecipitated protein in each lane. For western blots, $75 \mu \mathrm{g}$ total cellular protein was separated by 
SDS-PAGE on $10 \%$ resolving gels under denaturing and reducing conditions. Separated proteins were electroblotted to PVDF membranes according to the manufacturer's recommendations (Roche Molecular Biochemicals) and the blots were incubated with antibodies to human ER $\alpha$, SRC-1, p21, p27, extracellular signal regulated kinase 1 (ERK1), cyclin A, cyclin B, cyclin D1, cyclin E, cdk1, cdk2, cdk6, c-myc, and $\beta$-actin (Santa Cruz Biotechnology) for $16 \mathrm{~h}$ at $4{ }^{\circ} \mathrm{C}$. After washing in Tris-buffered saline containing $0 \cdot 1 \%$ Tween 20 (TBST, pH 7•4), blots were incubated for $30 \mathrm{~min}$ at room temperature with anti-IgG secondary antibody conjugated to horseradish peroxidase. Following extensive washing in TBST, bands were visualized by the enhanced chemiluminescence method (Roche Molecular Biochemicals) and quantitated using laser densitometry. Statistical analysis was performed by $t$-test.

\section{Transient transfection and reporter gene analysis}

Triplicate cultures of 50\% confluent SCC25 cells were transiently transfected with $5 \mu \mathrm{g}$ of the estrogen-responsive ERE-luc (estrogen response element fused to luciferase cDNA) or ERK1 promoter/reporter vectors (Chu et al. 2005) along with $2 \mu \mathrm{g}$ SRC-1, CBP, NCoR, or blank expression plasmids using Lipofectamine according to the manufacturer's recommendations (Invitrogen). One microgram $\beta$-galactosidase expression plasmid was used to normalize for transfection efficiency. Cultures were treated with $100 \mathrm{nM}$ E2, TAM, or vehicle for $24 \mathrm{~h}$. Cells were harvested and the reporter gene activity determined using a commercially available kit (Tropix, Bedford, MA, USA). Luciferase activity was normalized to $\beta$-galactosidase levels for each sample.

\section{Chromatin immunoprecipitation}

SCC25 clones were treated with $100 \mathrm{nM}$ E2, TAM, or vehicle for up to $4 \mathrm{~h}$. After washing in PBS, cells were fixed in $1 \%$ formaldehyde for $10 \mathrm{~min}$ at room temperature. The cells were washed in PBS and lysed in immunoprecipitation buffer containing protease inhibitors for $30 \mathrm{~min}$ at $4{ }^{\circ} \mathrm{C}$, sheared and centrifuged at $10000 \mathrm{~g}$ for $10 \mathrm{~min}$ and the supernatants were cleared with $2 \mu \mathrm{g}$ sheared salmon sperm DNA, $20 \mu \mathrm{l}$ preimmune serum, and $20 \mu \mathrm{l}$ protein $\mathrm{A} / \mathrm{G}$ sepharose beads for $2 \mathrm{~h}$ at $4{ }^{\circ} \mathrm{C}$. Aliquots of the supernatant were used as input DNA for normalization and amplified with $\beta$-actin PCR primers $\left(5^{\prime}\right.$-ACAGGAAGTCCCTTGCCATC- $3^{\prime}$ and 5'-ACTGGTCTCAAGTCAGTGTACAGG-3'). Immunoprecipitation using anti-SRC-1 or anti-CBP antibodies (Santa Cruz Biotechnology) was performed overnight at $4{ }^{\circ} \mathrm{C}$. Preimmune $\operatorname{IgG}$ was used as the negative control antibody. The immunoprecipitates were washed extensively in immunoprecipitation buffer, resuspended in $10 \mathrm{mM}$ Tris-HCl, $1 \mathrm{mM}$ EDTA (TE, $\mathrm{pH}$ 8) and incubated at $65^{\circ} \mathrm{C}$ for $6 \mathrm{~h}$ to reverse crosslinks. The supernatants were extracted with phenol/chloroform and ethanol precipitated. Following washing in $70 \%$ ethanol, pellets were dried and suspended in
$50 \mu \mathrm{l}$ TE. For PCR, $1 \mu \mathrm{l}$ template was amplified in buffer containing $10 \mathrm{mM}$ Tris- $\mathrm{HCl}(\mathrm{pH} 8 \cdot 3), 50 \mathrm{mM} \mathrm{KCl}$, $2.5 \mathrm{mM} \mathrm{MgCl}, 200 \mathrm{nM}$ each dNTP, and $100 \mathrm{ng}$ each primer (5'-CCACCACATAGAGAGCCTTTGG-3' and $5^{\prime}$-CACTCCTGCCGCCTCCCC- ${ }^{\prime}$ ) flanking the -390 to -10 region of the ERK1 promoter. The optimized cycle parameters were one cycle at $94^{\circ} \mathrm{C}$ for 3 min followed by 25 cycles of $94^{\circ} \mathrm{C}$ for $25 \mathrm{~s}, 55^{\circ} \mathrm{C}$ for $60 \mathrm{~s}, 72^{\circ} \mathrm{C}$ for $60 \mathrm{~s}$, and one final cycle at $72{ }^{\circ} \mathrm{C}$ for $10 \mathrm{~min}$. Amplified products were separated by agarose gel electrophoresis.

\section{Results}

To determine how estrogen receptor $\alpha(E R \alpha)$ signaling regulates proliferation of cancer cell lines derived from stratified squamous epithelium, we treated human SCC lines with E2 or TAM for up to 6 days. All SCC lines expressed low levels of $\mathrm{ER} \alpha$ as shown by immunoprecipitation (three representative lines shown in Fig. 1A). ER $\alpha$ mRNA levels were $75-90 \%$ lower than those observed in the $\mathrm{ER} \alpha$ positive human breast cancer cell line MCF7 (Fig. 1B; $P<0 \cdot 0001$ ). The ER $\alpha$ expression in the $E R \alpha$-negative breast cancer cell line MDA-MB-231 is shown for comparison. E2 treatment at concentrations up to $1000 \mathrm{nM}$ had no effect on the proliferation of human SCC lines in these assays. We next tested the effects of TAM treatment at concentrations from 10 to $1000 \mathrm{nM}$; maximal growth inhibition was achieved using the $100 \mathrm{nM}$ concentration. TAM, $100 \mathrm{nM}$, inhibited proliferation of SCC lines by $30-40 \%(P<0 \cdot 01)$ compared with vehicle-treated control cells, while $50 \mathrm{nM}$ TAM reduced growth by $15-20 \%$ (representative lines shown in Fig. 1C and $\mathrm{D} ; P<0 \cdot 05)$. The E2 effectively blocked the growth inhibitory effects of TAM when the two ligands were combined in culture, indicating that these effects were mediated through ER $\alpha$. To determine how TAM regulated cell cycle progression of SCC lines, we performed BrdU incorporation analysis and analyzed cell cycle regulatory protein expression. As shown in Fig. 2A, TAM reduced the percentage of BrdU-positive cells in the SCC4, SCC9, and SCC25 lines from 13 to 7\%, 14 to $7 \%$, and 16 to $9 \%$ respectively $(P<0 \cdot 02)$. E2 had no effect on BrdU incorporation in treated cell lines compared with control cultures. TAM treatment induced expression of the cyclindependent kinase inhibitor $\mathrm{p} 27^{\mathrm{Kip} 1}$ by sixfold in SCC4 and SCC9 cells (Fig. 2B). Expression of the G1/S phase cell cycle regulatory protein cyclin $\mathrm{E}$ was reduced by sevenfold in TAM-treated cells. Expression of the G1 cyclin-dependent kinase cdk6 also was inhibited by fivefold in TAM-treated SCC4 and SCC9 cells. We also examined expression of the estrogen target genes cyclin D1, c-myc, and p21 ${ }^{\mathrm{WAF} 1 / \mathrm{Cip} 1}$, but these protein levels were too low to be detected by western blot. These results indicate that, while TAM inhibited G1/S phase cell cycle progression of SCC lines, E2 had no effect on the proliferation of these cells.

We hypothesized that the lack of proliferative response to E2 and inhibitory effects of TAM may be due to differential 

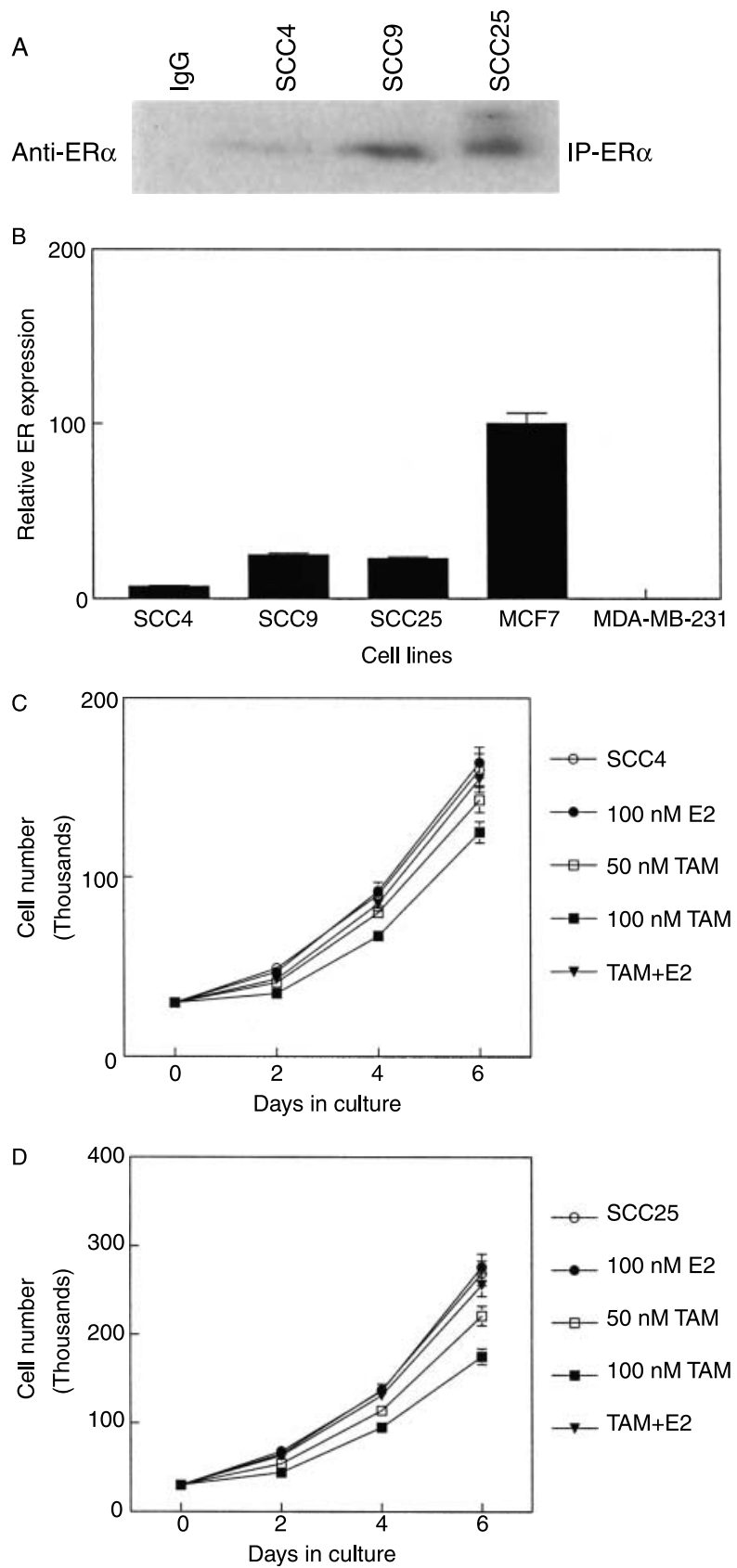

Figure 1 Differential proliferative response of human squamous cell carcinoma lines to E2 and tamoxifen. (A) Human SCC lines express low levels of estrogen receptor $\alpha$. ER $\alpha$ was immunoprecipitated from SCC lines using anti-ER $\alpha$ antibody (IP ER $\alpha$ ). Relative ER $\alpha$ expression was detected by incubating blots with anti-ER $\alpha$ antibody. Preimmune IgG was used as the negative control. These experiments were performed thrice with similar results. Representative blots are shown. (B) Comparison of relative $\mathrm{ER} \alpha$ expression between human SCC and breast cancer cell lines (MCF7, MDA-MB-231) by quantitative RT-PCR. (C and D) SCC4 and SCC25 cells were treated with $100 \mathrm{nM}$ $\mathrm{E} 2,50 \mathrm{nM}$ or $100 \mathrm{nM}$ tamoxifen (TAM), or $50 \mathrm{nM}$ each E2 and TAM (E2 + TAM) for 6 days. At 2-day intervals, triplicate cultures were counted using a hemacytometer. These experiments were performed thrice with similar results. Error bars represent S.E.M. recruitment of coactivator proteins to ER $\alpha$. To test this hypothesis, we immunoprecipitated ER $\alpha$ from three E2 and TAM-treated human SCC lines to examine interaction with coactivator proteins. Representative results from SCC25 cells are shown in Fig. 3. The E2 treatment dissociated the NCoR protein NCoR from ER $\alpha$ (Fig. 3A). In contrast, complex formation between $\mathrm{ER} \alpha$ and $\mathrm{NCoR}$ was increased threefold by TAM treatment compared with vehicle-treated control cultures. These results indicate that $\mathrm{NCoR}$ interaction with $\mathrm{ER} \alpha$ was largely intact in human SCC lines. Similarly, the coactivator protein $\mathrm{CBP}$ was recruited to $\mathrm{ER} \alpha$ in $\mathrm{E} 2$-treated
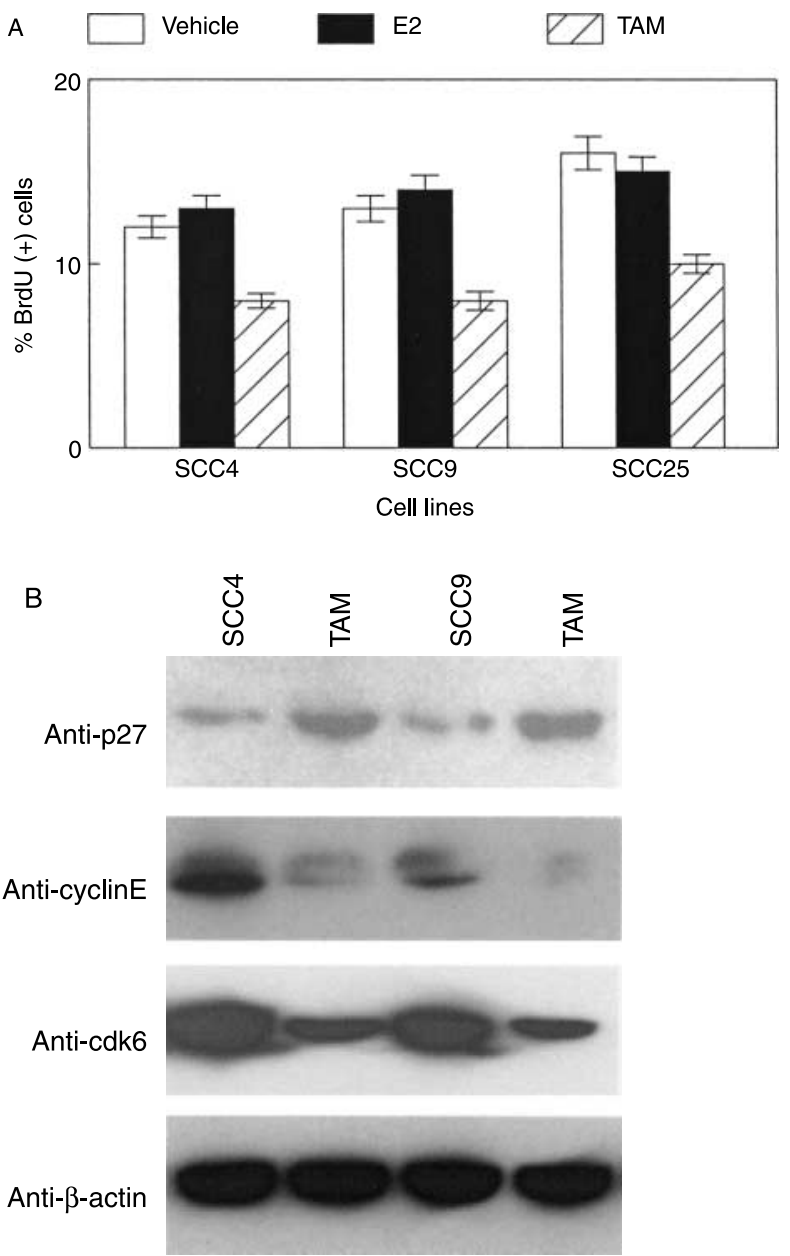

Figure 2 Tamoxifen treatment inhibits G1/S phase progression in human SCC lines. (A) SCC lines were treated with 100 nM E2 or tamoxifen (TAM) for $16 \mathrm{~h}$ before being labeled with BrdU as described in Materials and Methods. BrdU-positive cells were identified using immunofluorescence microscopy and reported as the percentage of total cells counted. These experiments were performed thrice with similar results. Error bars indicate S.E.M. (B) Tamoxifen treatment alters expression of G1/S phase cell cycle regulatory proteins. SCC lines were treated with $100 \mathrm{nM}$ tamoxifen (TAM) for $24 \mathrm{~h}$ prior to harvesting for western blotting using the antibodies indicated at left. These experiments were performed thrice with similar results. Representative blots are shown. 


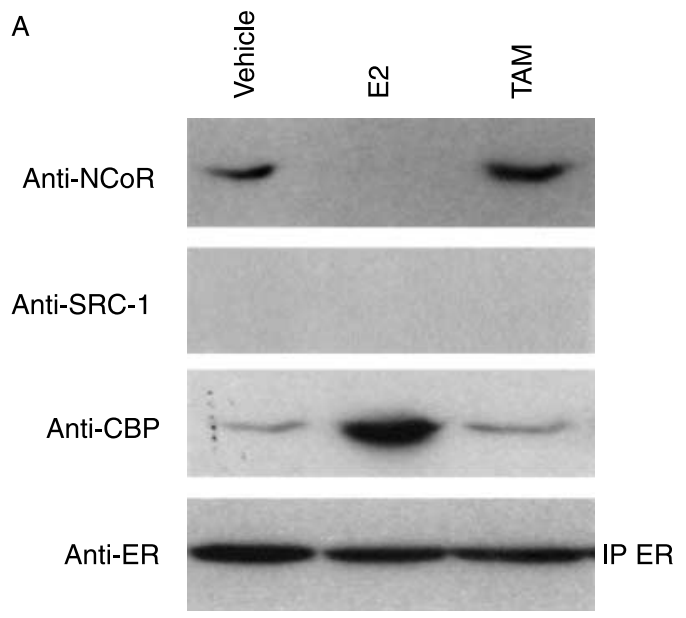

B

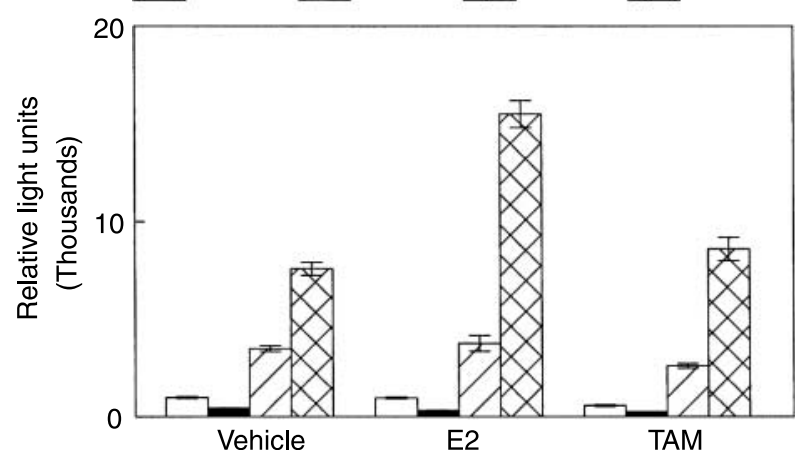

Figure 3 Estradiol and tamoxifen differentially recruit nuclear receptor repressors and activators to the estrogen receptor. (A) The SCC lines were treated with $100 \mathrm{nM}$ estradiol (E2), tamoxifen (TAM), or vehicle for $4 \mathrm{~h}$ prior to immunoprecipitation using anti-ER antibody (IP ER) as described in Materials and Methods. The blots were incubated with antibodies to the nuclear receptor repressor $\mathrm{NCoR}$ or the activators SRC- 1 and CBP to determine interaction with $E R \alpha$. These experiments were performed thrice with similar results. Representative blots are shown. (B) Differential regulation of an estrogen-responsive promoter element by ER $\alpha$ ligands, repressors, and activators. SCC lines were co-transfected with the estrogenresponsive ERE-luc reporter vector along with NCoR, CBP, or SRC-1 expression constructs. Triplicate transfected cultures were treated with $100 \mathrm{nM}$ estradiol (E2), tamoxifen (TAM), or vehicle as described in Materials and Methods. The activity of the luciferase reporter gene was expressed as relative light units normalized to the activity of a control reporter construct. These experiments were performed thrice with similar results. Error bars indicate S.E.M.

cells. This interaction was not observed in TAM-treated cells. Given that SRC-1 can interact with CBP, we expected that SRC-1 would co-immunoprecipitate with ER $\alpha$. However, we did not detect the presence of SRC-1 protein in the immunoprecipitated complexes from either E2 or TAMtreated cells. This lack of SRC-1 interaction with ER $\alpha$ transcriptional complexes made this coactivator a potential candidate for mediating E2 proliferative responses in human SCC lines. To determine if SRC-1 could enhance transcription from an $\mathrm{E} 2$ responsive promoter, we transiently transfected SRC-1, CBP, or NCoR with the ERE-luc reporter vector into E2 or TAM-treated SCC lines. Representative results from SCC25 cells are shown in Fig. 3B. SRC-1 induced the activity of the estrogenresponsive promoter by fourfold in vehicle-treated cells $(P<0 \cdot 01)$. This SRC-1-mediated transactivation was increased to sevenfold when transfected cells were treated with E2. However, TAM treatment repressed SRC-1 transactivation by $25 \%$ compared with vehicle-treated cells $(P<0 \cdot 05)$. CBP overexpression induced ERE-luc activity by threefold, although transactivation by this coactivator was less sensitive to E2 or TAM treatment $(P<0 \cdot 05)$. NCoR repressed the activity of the estrogen-responsive promoter by $50 \%(P<0 \cdot 02)$, which was largely unaffected by $\mathrm{E} 2$ or TAM treatment, likely due to overexpression of this corepressor protein. These results indicate that SRC-1 is a key mediator of the transcriptional response to $\mathrm{E} 2$ in human SCC lines.

SRC-1 protein expression was not detected in SCC lines by western blot (Fig. 4A). We created stable SRC-1 expressing clones in order to assess the effect of the coactivator on estrogen response in SCC lines. The expression of SRC-1 protein in stable clones is shown in Fig. 4A. To determine if SRC-1 protein could interact with ER $\alpha$ in these clones, we immunoprecipitated ER $\alpha$ from $E 2$ and TAM-treated cultures. E2 treatment recruited SRC-1 and CBP to ER $\alpha$ while displacing NCoR (Fig. 4B). Conversely, NCoR was strongly associated with ER $\alpha$ in TAM-treated cells. The SRC-1 interaction with ER $\alpha$ was undetectable in TAMtreated cells, and receptor association with CBP was reduced by twofold compared with vehicle-treated cultures. These results indicate that SRC-1 can form transcriptional protein complexes with CBP and ER $\alpha$ in SCC lines.

To determine the effect of $\mathrm{E} 2$ on proliferation of SRC-1 expressing clones, we treated SCC4 and SCC25 cells expressing SRC-1 protein or the neomycin resistance gene product with E2 for up to 6 days. As shown in Fig. 4C and D, SRC-1 expression produced $\mathrm{E} 2$ responsive increases in cellular proliferation in vitro. SCC4 clones expressing SRC1 protein proliferated $60 \%$ faster than control clones when treated with E2 $(P<0 \cdot 01)$. Additionally, SCC25 cells expressing SRC-1 protein proliferated 25\% faster than control clones when treated with E2 $(P<0 \cdot 05)$. TAM treatment inhibited proliferation of SRC-1 expressing clones similar to that observed in neomycin resistant cells, likely due to efficient recruitment of NCoR to ER $\alpha$ by TAM and SRC-1 displacement from the receptor in these clones. To determine how E2 regulated cell cycle progression in SRC-1 expressing clones, we examined G1/S phase progression and expression of cell cycle regulatory proteins by western blot. As shown in Fig. 4E, E2 treatment increased BrdU incorporation in SRC-1 expressing clones (13-19\% in SCC4 and 12-21\% in SCC25; $P<0 \cdot 05$ and $0 \cdot 04$ respectively). E2 treatment had no effect on neomycin resistant clones. $\mathrm{S}$ phase progression was inhibited to a similar degree by TAM treatment in both 

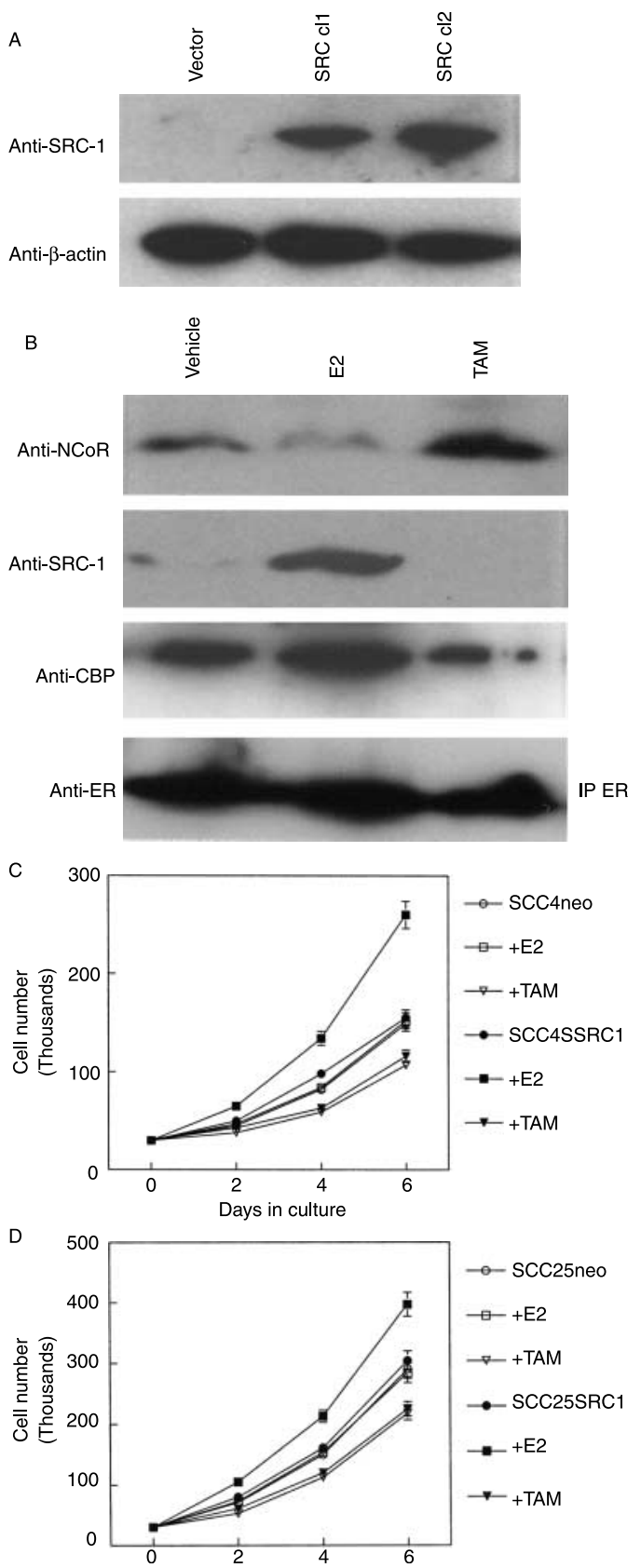

Journal of Endocrinology (2007) 193, 147-155

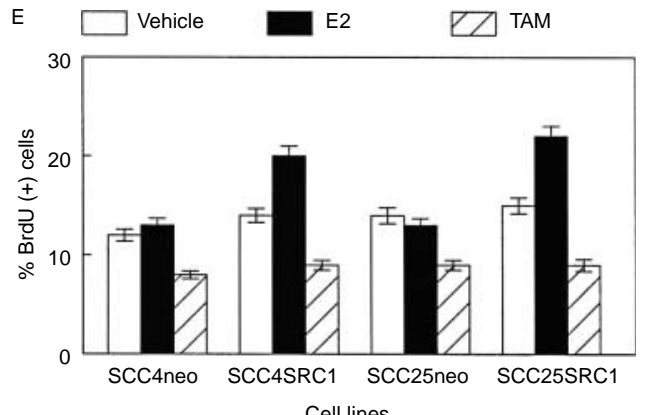

$\mathrm{F}$ Cell lines

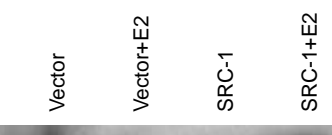

Anti-cyclin A

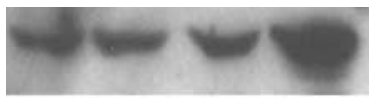

Anti-cyclin B

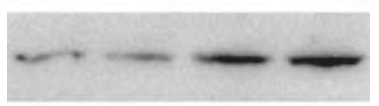

Anti-cdk1
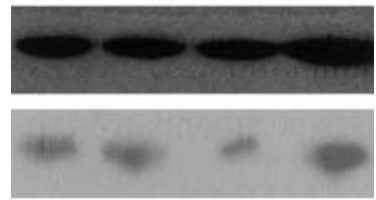

Anti- $\beta$-actin

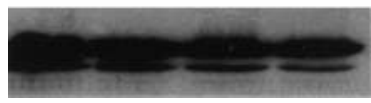

G
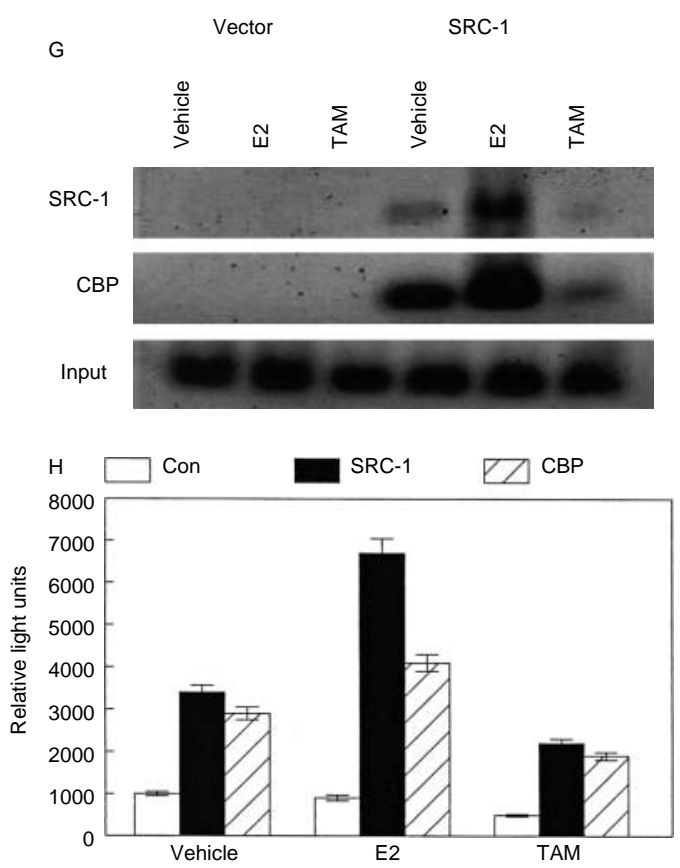

www.endocrinology-journals.org 
neomycin resistant and SRC-1 expressing clones. Expression of the mitogen-activated protein kinase ERK1 was induced threefold in SRC-1 expressing clones by E2 treatment (Fig. 4F). Expression of the S and G2 phase cyclins A and B was two- to three-fold higher in SRC-1 expressing clones, but was not affected by E2 treatment. Expression of the $\mathrm{S}$ phase cyclin-dependent kinase cdk2 was induced eightfold in SRC-1 expressing clones by E2 treatment, and the G2 phase kinase cdk1 was increased twofold. The E2 treatment had little effect on cell cycle regulatory protein expression in control clones. These results indicate that SRC-1 induces E2-mediated proliferation in human SCC lines.

To determine if transfected SRC-1 formed transcriptional complexes on chromatin, we performed ChIP on the proximal ERK1 promoter in E2 and TAM-treated SCC lines. The ERK1 expression was increased by E2 treatment in SRC-1 expressing clones (Fig. 4F). As shown in Fig. 4G, SRC-1 and CBP bound to the proximal ERK1 promoter in clones expressing SRC-1 but not in control cells. SRC-1 interaction with the proximal ERK1 promoter was increased by fivefold when SRC-1 clones were treated with E2. CBP interaction with the proximal ERK1 promoter increased threefold in E2-treated clones. TAM treatment reduced SRC-1 and CBP binding to the proximal ERK1 promoter. SRC-1 and CBP induced ERK1 promoter activity by threefold in reporter gene assays (Fig. 4H; $P<0 \cdot 04$ ). E2 treatment increased induction of the ERK1 promoter to sevenfold for SRC-1 $(P<0 \cdot 03)$ and fourfold for CBP $(P<$ $0 \cdot 02)$. TAM treatment inhibited ERK1 promoter activation by SRC-1 and CBP (twofold induction; $P<0 \cdot 05$ ). These results indicate that SRC-1 can form E2 responsive transcriptional complexes on the promoters of target genes in human SCC lines.

\section{Discussion}

The results of the present study have potentially important clinical ramifications in treatment of cancers from nonreproductive tissues. We showed that TAM inhibited proliferation of human SCC lines by inhibiting G1 to S phase progression. This inhibition correlated with the upregulation of $\mathrm{p} 27^{\mathrm{Kip} 1}$ expression and the downregulation of cyclin E and cdk6 protein levels. A similar mechanism of TAM-mediated growth inhibition was shown in human pancreatic cancer cell lines in which the anti-estrogen induced $\mathrm{p} 21^{\mathrm{WAF} 1 / \mathrm{Cip} 1}$ expression (Robinson et al. 1998). TAM upregulated $\mathrm{p} 21^{\mathrm{WAF} 1 / \mathrm{Cip} 1}$ and $\mathrm{p} 27^{\mathrm{Kip} 1}$ in human breast cancer cells and inhibited cyclin E-cdk2 kinase activity (Cariou et al. 2000). The p27 overexpression induced cell cycle arrest in TAM-treated breast cancer cell lines (Carroll et al. 2003). Initiation of cell cycle progression in these cells required dissociation of $\mathrm{NCoR}$ from $\mathrm{ER} \alpha$. We have demonstrated that TAM promoted complex formation between $\mathrm{NCoR}$ and ER $\alpha$ in agreement with the previous studies (Shang et al. 2000). NCoR has been shown to interact with helices 3 and 5 of the receptor ligand-binding domain in a TAM-dependent manner (Yamamoto et al. 2001). A tumorderived $E R \alpha$ mutant containing an amino acid substitution in helix 3 showed reduced interaction with NCoR and high

Figure 4 SRC-1 expression restores proliferative response to estradiol in human SCC lines. (A) SRC-1 expression in human SCC clones. SCC25 cells were stably transfected with a SRC-1 expression construct or blank vector as described in Materials and Methods. SRC-1 expression in stable clones (vector, SRC cl1, SRC cl2) was determined by western blot using anti-SRC-1 antibody. The blots were stripped and incubated with anti- $\beta$-actin antibody to determine relative amounts of protein in each lane. These experiments were performed thrice using different cell lines with similar results. Representative blots are shown. (B) Differential recruitment of NCoR and SRC-1 to ER $\alpha$ in response to estradiol and tamoxifen in SRC-1 stable clones. SCC25 clones were treated with vehicle, $100 \mathrm{nM}$ estradiol (E2), or $100 \mathrm{nM}$ tamoxifen (TAM) for $4 \mathrm{~h}$ as described in Materials and Methods. ER $\alpha$ was immunoprecipitated from cell lysates (IP ER) using anti-ER $\alpha$ antibody. The immunoprecipitated proteins were blotted and incubated with anti-NCoR, SRC-1, or CBP antibodies to determine complex formation and the blots were also incubated with anti-ER $\alpha$ antibody to determine relative amounts of the immunoprecipitated protein in each lane. These experiments were performed thrice using different clones with similar results. Representative blots are shown. (C and D) SRC-1 expression restores the proliferative response to estradiol in human SCC clones. SCC4 and SCC25 SRC-1 and neomycin resistant (neo) clones were treated with vehicle, $100 \mathrm{nM}$ estradiol (+E2), or $100 \mathrm{nM}$ tamoxifen (+TAM) for 6 days. At 2-day intervals, triplicate cultures were counted using a hemacytometer. These experiments were performed thrice with similar results. Error bars indicate s.E.M. (E) SRC-1 expression increases $S$ phase progression in E2-treated SCC clones. Neomycin resistant (neo) and SRC-1 expressing SCC4 and SCC25 clones were treated with $100 \mathrm{nM}$ estradiol (E2) or tamoxifen (TAM) for $16 \mathrm{~h}$ before being labeled with BrdU as described in Materials and Methods. BrdU-positive cells were identified using immunofluorescence microscopy and reported as the percentage of total cells counted. These experiments were performed thrice with similar results. Error bars indicate S.E.M. (F) Estradiol treatment induces cell cycle regulatory protein expression in SRC-1 expressing clones. SRC-1 and vector expressing clones were treated with $100 \mathrm{nM}$ estradiol (+E2) or vehicle for $24 \mathrm{~h}$ prior to protein extraction and western blotting using antibodies indicated at left. The blots were stripped and incubated with anti- $\beta$-actin antibody to determine relative amounts of protein in each lane. These experiments were performed thrice using different clones with similar results. Representative blots are shown. (G) SRC-1 and CBP are bound to the ERK1 promoter in estradiol-treated SCC clones. Chromatin immunoprecipitation using SRC-1 and CBP antibodies was performed as described in Materials and Methods using lysates from vehicle, estradiol, and tamoxifen-treated SRC-1 and vector expressing clones. Input genomic DNA was amplified prior to immunoprecipitation to determine relative amounts of DNA in each sample. These experiments were performed thrice using lysates from different clones with similar results. Representative gels are shown. (H) SRC-1 and CBP transactivate the ERK1 promoter. The ERK1 promoter was transiently cotransfected with SRC-1 or CBP expression vectors into triplicate cultures of SCC25 cells, which were treated with 100 nM estradiol (E2), tamoxifen (TAM), or vehicle for $24 \mathrm{~h}$ prior to harvesting for reporter gene assays. Luciferase activity was measured as relative light units normalized to the activity of a control reporter construct as described in Materials and Methods. These experiments were performed thrice with similar results. Error bars represent S.E.M. 
TAM-induced transcriptional activation. These preclinical studies suggest that TAM may be a useful clinical adjunct in cancers from non-reproductive tissues, perhaps in combination with standard chemotherapy agents (Tavassoli et al. 2002).

One of the key results of this study was the dependence on SRC-1 for E2-mediated proliferative response in cancer cells from non-reproductive tissues. Stratified squamous epithelia such as skin are E2 responsive (Kanda \& Watanabe 2004). Clinically, decreased estrogen levels associated with menopause correlate with epidermal thinning, and estrogen containing skin creams have been shown to increase epidermal thickness (Fuchs et al. 2003, Hall \& Phillips 2005). The $\mathrm{E} 2$ induces proliferation of neonatal keratinocytes in vitro, which express both $\mathrm{ER} \alpha$ and $\mathrm{ER} \beta$ (Verdier-Sevrain et al. 2004). ER $\beta$ was expressed by many cell types in skin from the human scalp, while ER $\alpha$ was localized to the dermal papilla and sebocytes (Thornton et al. 2003). However, a study using ER $\alpha$ null mutant mice indicated that only ER $\alpha$ mediated keratinocyte proliferation in vivo (Moverare et al. 2002). Little is known about SRC-1 expression in normal epidermal keratinocytes or ER $\alpha$ expression in SCCs, but the lack of E2 response in these cancers suggests that SRC-1 expression may be lost during carcinogenesis. One previous report demonstrated that TAM induced programmed cell death in SCC lines (Hoffmann et al. 2002), but only at high doses (up to $10 \mu \mathrm{M}$ ). TAM has been shown to have opposing effects on different tissues such as breast and uterus (Shang \& Brown 2002). The estrogenic effect of TAM in the uterus was shown to require high levels of SRC-1 expression. In mouse epidermis, TAM inhibits u.v.-induced DNA damage (Wei et al. 1998) and is used in clinical treatment of dendritic cellmediated allergic dermatitis (Yotsumoto et al. 2003). These studies suggest that as a potential chemotherapeutic agent, TAM would be more effective against cancer cells with low levels of coactivator expression.

Our results demonstrated that ERK1 expression is induced by SRC-1. This induction was mediated at the transcriptional level through direct interaction of SRC-1 and CBP with the proximal ERK1 promoter. These interactions were enhanced by E2 treatment and inhibited by cellular exposure to TAM. The proximal ERK1 promoter contains a number of transcription factor binding sites including those for AP-1 (Chu et al. 2005). The SRC-1 has been shown to bind directly to fos and jun subunits (Lee et al. 1998). Coexpression of CBP/p300 enhanced SRC-1-dependent transactivation, which was corroborated by our results using the ERK1 promoter. SR C-1 also has been shown to interact with serum response factor and enhances transactivation from this responsive element (Kim et al. 1998). Coexpression of $\mathrm{CBP} / \mathrm{p} 300$ also enhanced transactivation from serum response elements. Alternatively, ER $\alpha$ also has been shown to interact directly with and transactivate AP-1 subunits in vitro (Cheung et al. 2005). These results suggest the existence of multiple mechanisms by which E2 can activate target gene expression through coactivators.
In summary, we show that SRC-1 was a key molecular determinant of estrogen-mediated proliferation in human SCC lines. TAM treatment inhibited cell cycle progression and proliferation of human cancer lines derived from stratified squamous epithelium. SRC-1 expression was not detected in these SCC lines; however, transient transfection of SRC-1, $\mathrm{CBP}$, or both coactivators enhanced transactivation of an estrogen-responsive promoter in cancer cells treated with E2 or TAM. SRC-1 expression restored the E2-mediated proliferative response to human SCC lines. This increased proliferation correlated with increased ERK1 expression. SRC-1 and CBP were recruited to the proximal ERK1 promoter region in E2 but not TAM-treated cells. Future studies will focus on specific interactions of SRC-1 and CBP with transcription factor response elements in the proximal ERK1 promoter and examine the role of ER $\beta$ in SCC proliferation.

\section{Acknowledgements}

We thank Dr Ronald Evans for expression vectors and Dr Gilles Pages for the ERK1 promoter construct. This study was supported by American Institute of Cancer Research grant $05 \mathrm{~A} 026$. The authors declare that there is no conflict of interest that would prejudice the impartiality of this scientific work.

\section{References}

Cariou S, Donovan JC, Flanagan WM, Milic A, Bhattacharya N \& Slingerland JM 2000 Downregulation of $\mathrm{p} 21^{\mathrm{WAF} 1 / \mathrm{Cip} 1}$ or $\mathrm{p} 27^{\mathrm{Kip} 1}$ abrogates antiestrogen mediated cell cycle arrest in human breast cancer cells. PNAS 97 9042-9046.

Carroll JS, Lynch DK, Swarbrick A, Renoir JM, Sarcevic B, Daly RJ, Musgrove EA \& Sutherland RL 2003 p $27^{\text {Kip } 1}$ induces quiescence and growth factor insensitivity in tamoxifen treated breast cancer cells. Cancer Research 63 4322-4326.

Cheung E, Acevedo ML, Cole PA \& Kraus WL 2005 Altered pharmacology and distinct coactivator usage for estrogen receptor dependent transcription through activating protein 1. PNAS 102 559-564.

Chien PY, Ito M, Park Y, Tagami T, Gehm BD \& Jameson JL 1999 A fusion protein of the estrogen receptor (ER) and nuclear receptor corepressor (NCoR) strongly inhibits estrogen dependent responses in breast cancer cells. Molecular Endocrinology 13 2122-2136.

Chu BY, Tran KV, Ku TKS \& Crowe DL 2005 Regulation of ERK1 gene expression by coactivator proteins. Biochemical Journal 392 589-599.

Couse JF \& Korach KS 1999 Estrogen receptor null mice: what have we learned and where will they lead us? Endocrine Reviews 20 358-417.

Ercoli A, Scambia G, Fattorossi A, Raspaglio G, Battaglia A, Cicchillitti L, Malorni W, Rainaldi G, Benedetti Panici P \& Mancuso S 1998 Comparative study on the induction of cytostasis and apoptosis by ICI 182,780 and tamoxifen in an estrogen receptor negative ovarian cancer cell line. International Journal of Oncology 76 47-54.

Fuchs KO, Solis O, Tapawan R \& Paranjpe J 2003 The effects of an estrogen and glycolic acid cream on the facial skin of postmenopausal women: a randomized histologic study. Cutis 71 481-488.

Hall G \& Phillips TJ 2005 Estrogen and skin: the effects of estrogen, menopause, and hormone replacement therapy on the skin. Journal of the American Academy of Dermatology 53 555-568. 
Hoffmann TK, Bojar H, Eckel J, van Lierop A, Balz V, Friebe-Hoffmann U, Hauser U \& Bier H 2002 Effects of tamoxifen on human squamous cell carcinoma lines of the head and neck. Anti-Cancer Drugs 13 521-531.

Huang HJ, Norris JD \& McDonnell DP 2002 Identification of a negative regulatory surface within estrogen receptor $\alpha$ provides evidence in support of a role for corepressors in regulating cellular responses to agonists and antagonists. Molecular Endocrinology 16 1778-1792.

Kanda N \& Watanabe S 2004 17ß-Estradiol stimulates the growth of human keratinocytes by inducing cyclin D2 expression. Journal of Investigative Dermatology 123 319-328.

Kim HJ, Kim JH \& Lee JW 1998 Steroid receptor coactivator 1 interacts with serum response factor and coactivates serum response element mediated transactivations. Journal of Biological Chemistry 273 28564-28567.

Kim MY, Hsiao SJ \& Kraus WLA 2001 A role for coactivators and histone acetylation in estrogen receptor $\alpha$ mediated transcription initiation. EMBO Journal 20 6084-6094.

Kornberg RD \& Lorch Y 1999 Chromatin modifying and remodeling complexes. Current Opinion in Genetics and Development 9 148-151.

Lee SK, Kim HJ, Na SY, Kim TS, Choi HS, Im SY \& Lee JW 1998 Steroid receptor coactivator 1 coactivates activating protein 1 mediated transactivations through interaction with the c-jun and c-fos subunits. Journal of Biological Chemistry 273 16651-16654.

Lindner DJ \& Borden EC 1997 Synergistic antitumor effects of a combination of interferon and tamoxifen on estrogen receptor positive and receptor negative human tumor cell lines in vivo and in vitro. Journal of Interferon and Cytokine Research 17 681-693.

Mangelsdorf DJ, Thummel C, Beato M, Herrlich P, Schutz G, Umesono K, Blumberg B, Kastner P, Mark M, Chambon P et al. 1995 The nuclear receptor superfamily: the second decade. Cell $\mathbf{8 3} 835-839$.

Moverare S, Lindberg MK, Faergemann J, Gustafsson JA \& Ohlsson C 2002 Estrogen receptor $\alpha$, but not estrogen receptor $\beta$, is involved in the regulation of the hair follicle cycling as well as the thickness of epidermis in male mice. Journal of Experimental Dermatology 119 1053-1058.

Needham M, Raines S, McPheat J, Stacey C, Ellston J, Hoare S \& Parker M 2000 Differential interaction of steroid hormone receptors with LXXLL motifs in SRC-1a depends on residues flanking the motif. Journal of Steroid Biochemistry and Molecular Biology 72 35-46.

Ojanotko-Harri A, Forssell H, Laine M, Hurttia H, Blauer M \& Tuohimaa P 1992 Immunohistochemical detection of androgen receptors in human oral mucosa. Archives of Oral Biology 37 511-514.

Ratajczak T 2001 Protein coregulators that mediate estrogen receptor function. Reproduction, Fertility and Development 13 221-229.

Robinson EK, Grau AM, Evans DB, Smid CM, Chiao PJ, Abbruzzese JL \& Grimm EA 1998 Cell cycle regulation of human pancreatic cancer by tamoxifen. Annals of Surgical Oncology 5 342-349.

Robyr D, Wolffe AP \& Wahli W 2000 Nuclear hormone receptor coregulators in action: diversity for shared tasks. Molecular Endocrinology 14 329-347.

Shang Y \& Brown M 2002 Molecular determinants for the tissue specificity of SERMs. Science 295 2465-2468.
Shang Y, Hu X, DiRenzo J, Lazar MA \& Brown M 2000 Cofactor dynamics and sufficiency in estrogen receptor regulated transcription. Cell 103 843-852.

Sheppard HM, Harries JC, Hussain S, Bevan C \& Heery DM 2001 Analysis of the steroid receptor coactivator 1 (SRC1)-CREB binding protein interaction interface and its importance for the function of SRC1. Molecular and Cellular Biology 21 39-50.

Smith CL, Onate SA, Tsai MJ \& O'Malley BM 1996 CREB binding protein acts synergistically with steroid receptor coactivator 1 to enhance steroid receptor dependent transcription. PNAS 93 8884-8888.

Son ED, Lee JY, Lee S, Kim MS, Lee BG, Chang IS \& Chung JH 2005 Topical application of $17 \beta$-estradiol increases extracellular matrix protein synthesis by stimulating TGF- $\beta$ signaling in aged human skin in vivo. Journal of Investigative Dermatology 124 1149-1161.

Spencer TE, Jenster G, Burcin MM, Allis CD, Zhou J, Mizzen CA, McKenna NJ, Onate SA, Tsai SY, Tsai MJ et al. 1997 Steroid receptor coactivator 1 is a histone acetyltransferase. Nature 389 194-198.

Tavassoli M, Soltaninia J, Rudnicka J, Mashanyare D, Johnson N \& Gaken J 2002 Tamoxifen inhibits the growth of head and neck cancer cells and sensitizes these cells to cisplatin induced apoptosis: role of TGF $\beta 1$. Carcinogenesis 23 1569-1575.

Thornton MJ 2002 The biological actions of estrogens on skin. Experimental Dermatology 11 487-502.

Thornton MJ, Taylor AH, Mulligan K, Al-Azzawi F, Lyon CC, O’Driscoll J \& Messenger AG 2003 Oestrogen receptor beta is the predominant oestrogen receptor in human scalp skin. Experimental Dermatology 12 181-190.

Verdier-Sevrain S, Yaar M, Cantatore J, Traish A \& Gilchrest BA 2004 Estradiol induces proliferation of keratinocytes via a receptor mediated mechanism. FASEB Journal 18 1252-1254.

Wei H, Cai Q, Tian L \& Lebwohl M 1998 Tamoxifen reduces endogenous and UV light induced oxidative damage to DNA, lipid, and protein in vitro and in vivo. Carcinogenesis 19 1013-1018.

Xu JM, Qiu Y, DeMayo FJ, Tsai SY, Tsai MJ \& O’Malley BW 1998 Partial hormone resistance in mice with disruption of the steroid receptor coactivator 1 (SRC-1) gene. Science 279 1922-1925.

Yamamoto Y, Wada O, Suzawa M, Yogiashi Y, Yano T, Kato S \& Yanagisawa J 2001 The tamoxifen responsive estrogen receptor $\alpha$ mutant D351Y shows reduced tamoxifen dependent interaction with corepressor complexes. Journal of Biological Chemistry 276 42684-42691.

Yotsumoto S, Shimomai K, Hashiguchi T, Uchimiya H, Usuki K, Nishi M, Kanekura T \& Kanzaki T 2003 Estrogen dermatitis: a dendritic cell mediated allergic condition. Dermotology 207 265-268.

Received in final form 21 December 2006

Accepted 4 January 2007

Made available online as an Accepted Preprint 25 January 2007 